\title{
Perspectivas sobre el patrimonio documental publicitario. Un estudio de caso en el panorama español: las agencias RECLAM y Está Pasando
}

\author{
Alicia Parras-Parras*, Julia Rodríguez-Cela* \\ *Facultad de Ciencias de la Información, Universidad Complutense de Madrid \\ Correo-e: aparras@ucm.es | ORCID iD: https://orcid.org/0000-0002-7186-1065 \\ Correo-e: jurodrig@ucm.es | ORCID iD: https://orcid.org/0000-0002-9170-8025
}

Recibido: 24-06-20; $2^{a}$ versión: 03-08-20; Aceptado: 14-9-20; Publicado: 06-07-21

Cómo citar este artículo/Citation: Parras-Parras, A.; Rodríguez-Cela, J. (2021). Perspectivas sobre el patrimonio documental publicitario. Un estudio de caso en el panorama español: las agencias RECLAM y Está Pasando. Revista Española de Documentación Científica, 44 (3), e302. https://doi.org/ 10.3989/redc.2021.3.1809

\begin{abstract}
Resumen: Esta investigación analiza la importancia que el patrimonio publicitario tiene en dos agencias de publicidad españolas: RECLAM, ubicada en Galicia y con una trayectoria de ochenta años; y Está Pasando creada en 2014 y con sede en Madrid. A través de un estudio de caso comparativo se llega a las siguientes conclusiones: 1 ) falta de concienciación en cuanto a la necesidad de conservar el patrimonio documental que generan las agencias de publicidad; 2) el patrimonio publicitario genera un valor añadido que puede utilizarse en el seno de la agencia para producir nuevas campañas y para promocionarse; 3 ) necesidad de incorporar en el sector publicitario profesionales de la documentación capaces de asumir tareas que permitan conservar las campañas y generar el archivo de la agencia.
\end{abstract}

Palabras Clave: patrimonio documental publicitario; agencia RECLAM, agencia Está Pasando; digitalización; archivo publicitario; gestión documental publicitaria.

Perspectives on documentary advertising heritage. A case study in the Spanish panorama: RECLAM and Está Pasando agencies

Abstract: This research analyzes the importance that advertising heritage has in two Spanish advertising agencies: RECLAM, located in Galicia and with a history of eighty years; and Está Pasando created in 2014 and based in Madrid. The following conclusions are reached through a comparative case study: 1) Lack of awareness regarding the need to preserve the documentary heritage generated by these advertising agencies; 2) Advertising heritage is able to generate added value that can be used within the agency to produce new campaigns and to promote itself through social media, for example; 3) It is urgent to incorporate documentation professionals in the advertising sector capable of assuming tasks that allow the preservation of campaigns and the creation of the agency archive.

Keywords: advertising heritage; RECLAM advertising agency; Está Pasando advertising agency; digitization; advertising archive; advertising documentary management.

Copyright: (c) 2021 CSIC. Este es un artículo de acceso abierto distribuido bajo los términos de la licencia de uso y distribución Creative Commons Reconocimiento 4.0 Internacional (CC BY 4.0). 


\section{INTRODUCCIÓN}

La publicidad es de todas las ciencias de la información aquella cuyo proceso se antoja más inmediato. $Y$ afirmamos esto desde la conciencia de pertenecer a una modernidad líquida -que ya preconizó Zygmunt Bauman hace años- y exigente, que obliga a casi todos los órdenes de la sociedad actual, personales y profesionales, a una constante adaptación al medio. Sin embargo, la actividad publicitaria es mucho más que una profesión o que una disciplina porque, reconozcámoslo, al cabo del tiempo, echando la vista atrás, la publicidad -spots, cuñas, piezas gráficas, e incluso mañana, memes- nos dirá lo que somos o, al menos, lo que fuimos. Por tanto, el patrimonio que genera la publicidad es importante, sin duda, pero son muchas las cuestiones que asaltan a cualquier experto en documentación publicitaria, algunas de estas preguntas se realizan desde la perspectiva histórica -¿qué se ha conservado? -, pero otras deben realizarse con el objetivo de prever las demandas de información futuras e incluso enriquecer el proceso creativo inherente a cualquier campaña. Como señala Marcos-Recio (2018):

"Es hora de que ese patrimonio sea activo, tome vida y se pueda consultar. La publicidad tiene y muestra un valor más allá del anuncio y su tiempo de exhibición. Lo que queda es tan importante para la historia de la humanidad, como lo es para el anunciante que pretende vender su producto y obtener beneficios".

La publicidad hoy, enmarcada en la complejidad del mundo digital, vive un cambio de paradigma que ha afectado profundamente a la relación entre anunciante y agencia, acelerando los procesos creativos y ejecutivos como consecuencia -lógica- de la sociedad de consumo, líquida, que demanda nuevas necesidades en canales que hace tan sólo unos lustros eran impensables, como las redes sociales. En este artículo veremos las diferentes perspectivas de la gestión del patrimonio publicitario de dos agencias españolas: RECLAM, fundada en A Coruña en 1940, y Está Pasando, de reciente creación (2014) y ubicada en Madrid.

\section{ESTADO DE LA CUESTIÓN}

A continuación, se profundizará en dos cuestiones básicas que nos permitirán conocer investigaciones sobre el patrimonio publicitario y su importancia, así como el contexto publicitario actual en el que las dos agencias que son objeto de investigación se insertan.

\subsection{Breve panorama de la gestión del patri- monio publicitario en España}

La historia de la publicidad, como objeto de investigación y como punto de partida necesario para conocer la situación del patrimonio publicitario en la actualidad, ha estado siempre vinculada a nombres propios y relevantes de la universidad española. En este sentido, debemos mencionar en primer lugar el ímprobo trabajo del catedrático Raúl Eguizábal Maza, de la Facultad de Ciencias de la Información de la Universidad Complutense de Madrid. Su libro, Historia de la publicidad (2011), reúne en un apéndice las peculiaridades de la evolución de esta actividad en nuestro país, desde el punto de vista del negocio, pero también de su idiosincrasia, fruto de la relación entre la publicidad y la influencia que los avatares sociales del siglo XX tuvieron en ella. Otra aproximación histórica y necesaria para sustentar los pilares de esta y muchas otras investigaciones es el trabajo de Fernández-Poyatos (2010) sobre las primeras agencias de publicidad en España (1912-1924). Otros autores recogen en sus obras descubrimientos sobre la historia de la publicidad española en otros períodos, como es el caso de la obra Una historia de la publicidad y el consumidor en España. 50 aniversario (1965-2015), de Fernando Montañés (2015). Otras investigaciones, que también hunden sus raíces en la cuestión histórica, se centran en conocer aspectos más concretos, como la publicidad política e institucional (Orbea-Mira, 2008) (De Andrés del Campo y González-Martín, 2010), (Cortés-González, 2011); la publicidad exterior (Pacheco Rueda, $1998,2000,2004$ y 2008); la fotografía en publicidad (Coronado e Hijón, 2000), (Eguizábal-Maza, 2001, 2003), (Sánchez-Vigil, 2009), (Marcos-Recio, y otros, 2005).

La preocupación por conocer el patrimonio publicitario español y llevar a cabo ciertas propuestas de mejora, poniendo de relieve la necesidad de conservar y difundir las piezas publicitarias creadas en el seno de las agencias españolas, también se ha visto -afortunadamente- reflejada en trabajos académicos y de investigación que debaten en sus páginas algunas cuestiones o retos que podemos sistematizar en las siguientes categorías: sinergias entre creatividad y patrimonio ${ }^{1}$, ahorro de costes (reutilización de imágenes o piezas de diseño gráfico); y, por último, el conocimiento histórico de tendencias sociales. En este sentido podemos citar a perfumerías Gal, empresa que conservó los envases de sus productos y gracias a ello es posible conocer los gustos de otra época (Marcos-Recio y otros, 2018).

En cualquier caso, y pese a que en España no contamos con un museo dedicado íntegramente a la publicidad, merece la pena recordar que existen ciertas iniciativas institucionales que conservan y difunden una parte del patrimonio publicitario español, como, por ejemplo, la Biblioteca Nacional 
(BNE). Este organismo atesora las colecciones, en parte digitalizadas, de "Ephemera", -que incluye curiosos documentos como etiquetas y envoltorios de productos, calendarios, prospectos comerciales, paipáis publicitarios o cromos troquelados,- y "Carteles" -publicitarios: de ferias, exposiciones y congresos, de promoción turística, de alimentación, de salud, belleza y moda; espectáculos, fiestas y eventos deportivos: de circo, taurinos, de teatro y cine, etc.; propagandísticos: políticos y religiosos.

Otra iniciativa relevante fue la creación del Museo Virtual de Arte Publicitario (MUVAP) en el año 2001. Este museo fue impulsado por la Asociación General de Empresarios de publicidad (AGEP) y la Federación Nacional Empresas de Publicidad (FNEP) y apoyado por el Centro Virtual Cervantes (Vicente-Domínguez, 2017). Sin embargo, y pese a su interesante recorrido por una parte importante del singular acervo publicitario español -hablamos de carteles turísticos de España durante la Guerra Civil o los anuarios del Club de Creativos entre 1999 y $2008-$, la virtualidad del museo se limita al visionado de carteles y otras piezas gráficas, como señala Marcos-Recio (2018): "la virtualidad se supone que tiene que ver con la interactividad, con la participación de los que llegan al sitio web, con la posibilidad de ampliar y mejorar lo que ya existe".

Y si bien en el párrafo anterior se hablaba de un museo de la publicidad virtual, no debemos olvidar que, desde hace unos años, el Museo Nacional de Artes Decorativas ha dedicado sus exposiciones a difundir el trabajo de publicitarios españoles, como el Grupo 13, que innovó especialmente en el campo del diseño gráfico (González-Solas, 2018).

\subsection{Centros de documentación en publicidad}

Mientras que los centros de documentación son una estructura indispensable en algunos medios de comunicación, como la televisión, la prensa y la radio, parece que en el ámbito de la profesión publicitaria estos centros se organizan como estructuras empresariales independientes a las agencias, si bien sabemos que, a principios del siglo veintiuno, algunas de las grandes agencias multinacionales -Tiempo BBDO, Publicis o Grey- si contaban con estas estructuras 0 , al menos, había personal formado que realizaba tareas documentales en dos sentidos: seleccionar y conservar fuentes de información útiles para el proceso creativo de la agencia (anuarios, diarios, revistas del sector, informes), ofrecérselas al publicitario y gestionar otras necesidades como la adquisición de videos o fotografías. Y, por último, realizar el clipping, que implica el seguimiento en medios de la pieza publicitaria y su recopilación. (Marcos-Recio, 2002).
Las autoras apuntan como posibles causas de la práctica inexistencia de centros o departamentos de documentación en el seno de las agencias españolas la crisis económica de 2008 -que supuso el adelgazamiento de las estructuras empresariales como consecuencia lógica de la caída de la inversión publicitaria ${ }^{2}-$, y la irrupción de Internet con la consecuente facilidad e inmediatez a la hora de obtener información.

Sin embargo, lo anterior no exime a las agencias de la necesidad de contar con centros de documentación o, al menos, con documentalistas especializados en la práctica publicitaria. Estos profesionales pueden trabajar en estrecha colaboración con el equipo creativo en la elaboración de informes de tendencias y de buenas prácticas (benchmarking) con el objetivo de conocer qué acciones de éxito han llevado a cabo otras agencias o marcas de la competencia.

No obstante, existen iniciativas privadas y públicas que tratan de suplir externamente la falta de centros de documentación internos y que se encargan de custodiar campañas -patrimonio, al fin y al cabo- que, de otro modo, podrían incluso desaparecer en medio de la -casi retórica- pregunta: ¿quién debe conservar una campaña: el anunciante o la agencia?

En este sentido, deben destacarse el Centro de Documentación Publicitaria y Publidocnet. Mientras que el primero cumple la función de archivo histórico que comercializa piezas gráficas, campañas, y fotografías publicitarias, entre otros, y que se remontan a finales del siglo diecinueve, Publidocnet es una iniciativa puesta en marcha por el profesor Juan Carlos Marcos-Recio y respaldada por la Universidad Complutense de Madrid que, además de conservar digitalmente las campañas de radio, televisión, cine, exterior o prensa, da cabida a las últimas investigaciones y noticias del sector.

\subsection{Contexto actual de la publicidad en España}

A lo largo de estas páginas se ha argumentado por qué es importante conocer el legado que la publicidad nos ha dejado, desde que se erige como una profesión moderna -algunos autores, como Prat Gaballí, señalan ese momento entre 1850 y 1895, en la Segunda Revolución Industrial, (Fernández-Poyatos, 2013)- hasta hoy. Sin embargo, la publicidad ha cambiado tangencialmente en las últimas décadas, sobre todo desde la irrupción de Internet y las redes sociales, que han ampliado las fronteras de la creatividad. Y para ilustrar la preeminencia de la comunicación digital se aporta un dato: la inversión en publicidad digital en el año 2019 se ha incrementado hasta un $38,6 \%$ del total 
Figura 1. Evolución de la inversión publicitaria en Internet en España (2007-2019).

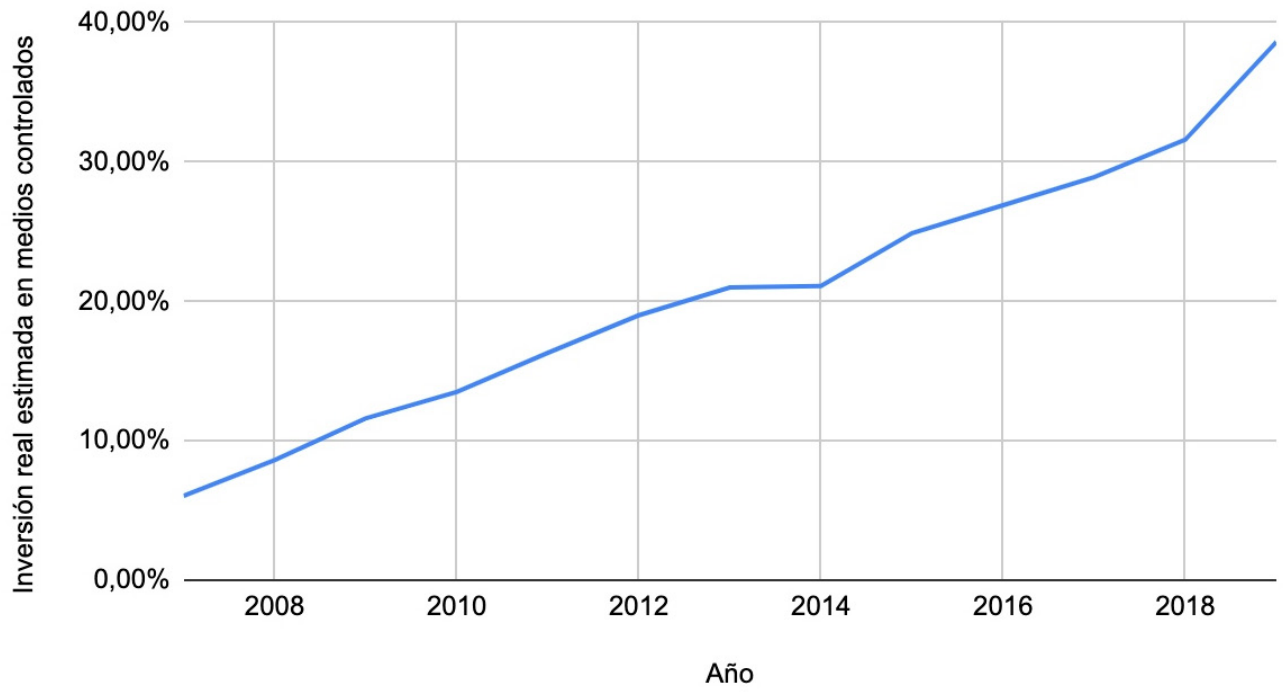

Fuente: datos extraídos de los informes anuales de Infoadex (2007-2019)

de la inversión real estimada en medios controlados $^{3}$, desbancando del primer puesto a la televisión $(33,7 \%)$ (Infoadex, 2020).

En este panorama se observa el paso de una profesión que hasta ahora debía atender a las necesidades de comunicación de muchos anunciantes en pocos medios (televisión, radio, cine, prensa y acciones below the line), a una profesión que atiende a muchos anunciantes en un medio muy diversificado: Internet. Lejos queda la época en la que "hablar sobre el producto era suficiente"; hoy, en España hay 42,40 millones de usuarios de Internet y las redes sociales son utilizadas dos horas al día de media por 29 millones de españoles, según el último informe de We Are Social (2020). En este contexto tecnológico, los nuevos medios ofrecen a las marcas la posibilidad de llegar a un público muy concreto, establecer una relación bidireccional y duradera a través de la creación de comunidades y conocer con relativa facilidad a cuántas personas del público objetivo se ha llegado gracias a métricas sencillas que permiten valorar si se han alcanzado los KPIs previamente establecidos por anunciante $\mathrm{y} / \mathrm{o}$ agencia.

No podemos negar, por tanto, que conceptos como engagement, viralidad, comunicación transmedia, influencer o prosumidor, están presentes en todas las estrategias digitales que los publicitarios idean para llegar a un consumidor cuyos patrones de consumo son cada vez más cambiantes y complejos ${ }^{4}$ :

La brusca fragmentación de la audiencia con la eclosión de los nuevos medios, la aparición de múltiples dispositivos para acceder a contenidos desde nuevas plataformas y canales bidireccionales, la posibilidad que se brinda al consumidor de participar en la conversación con las marcas, enriquecerla y hacerla más creíble, ha provocado una profunda mutación en la estrategia de negocio de la empresa publicitaria y en los perfiles profesionales que la integran (De Salas-Nestares y otros, 2019).

Por lo tanto, hay dos cuestiones clave en el contexto actual de la publicidad: el consumidor es también productor de contenidos y debe ser tenido en cuenta por las marcas - de ahí, el concepto de prosumidor- y el cambio en los procesos y en la organización interna de las agencias publicitarias, que tienen un organigrama más horizontal. Así, la relación con el cliente se fortalece al desaparecer las barreras físicas, por ejemplo, a través del email o de las reuniones en videoconferencias o calls, facilitando el feedback y las aprobaciones que guían cada proyecto en la dirección correcta. Además, las fronteras de los departamentos en el seno de las agencias se diluyen porque la mayoría de proyectos exigen el trabajo coordinado de ejecutivos de cuentas, duplas, community managers, planners y digital strategists ${ }^{5}$ necesitando en ocasiones la externalización de algunos servicios que, por diferentes razones, no se ofrecen in-house, por ejemplo, aquellos prestados por profesionales especializados en e-commerce, data research, programmatic media, performance search affiliate, videogaming (...) (De-Salas-Nestares y otros, 2019). 


\section{OBJETIVOS Y METODOLOGÍA}

Esta investigación se plantea conocer cómo dos agencias publicitarias españolas de tamaño medio, pero muy diferentes en cuanto a trayectoria, valoran, gestionan y conservan el patrimonio publicitario que generan en su actividad profesional.

Para alcanzar este objetivo se emplea una metodología cualitativa de estudio de casos de tipo ilustrativa -con el fin de poner de manifiesto las prácticas de gestión de empresas del sector (Yin, 1994, citado en Castro-Monge, 2010)- y múltiple, ya que se analizarán dos casos a los que se les aplicarán las mismas categorías de estudio para, finalmente, hacer una comparación que ponga de manifiesto las posibles semejanzas y diferencias encontradas en ambas agencias publicitarias. Esta metodología se ha elegido por dos razones: en primer lugar, por su naturaleza holística, que permite al investigador observar la realidad en profundidad y ofrecer una visión total del objeto de estudio -en este caso la gestión del patrimonio publicitario en dos agencias españolas-; y, por otro lado, el estudio de casos ayuda a advertir de las peculiaridades y diferencias de cada fenómeno investigado (Álvarez-Álvarez y San Fabián-Maroto, 2012).

Las dos agencias se seleccionaron por muestreo de conveniencia, deliberado e intencional, por su tamaño similar y accesibilidad, así como por su diferente ubicación en la geografía española y trayectoria: agencias: @RECLAMpubli y @esta_pasando_agencia), credenciales de agencia en Está Pasando y book de agencia de RECLAM.

B. Observación guiada: visita de las autoras a ambas agencias de publicidad. En el caso de $R E-$ CLAM esta visita se realizó el 20 de enero de 2020 y en el caso de Está Pasando el 5 de febrero de 2020.

C. Entrevistas en profundidad presenciales semi-estructuradas a dos directivos de cada agencia: Lis Torrón Alabaú, directora creativa ejecutiva de RECLAM, y Jacobo Prieto Martínez, director creativo ejecutivo de Está Pasando.

D. Artefactos físicos, tecnológicos y culturales: piezas gráficas de archivo y audiovisuales de ambas agencias para complementar los datos y la información obtenida a través de las fuentes anteriores.

La información principal proviene de las dos entrevistas en profundidad y semiestructuradas que realizaron las autoras entre enero y febrero de 2020 a los directores creativos ejecutivos de las dos agencias. Las preguntas de estas entrevistas se prepararon con el fin de dar respuesta al objetivo principal de la investigación y siguiendo las pautas de McNamara (2009), citado en Turner, 2010) a) la redacción debe ser abierta para que los encuestados puedan elegir sus propios términos a la hora de responder a las preguntas; b) las pregun-

Tabla I. Datos de las agencias de publicidad seleccionadas para el estudio de caso (enero de 2020).

\begin{tabular}{|l|c|c|c|c|c|}
\hline & $\begin{array}{c}\text { Año de } \\
\text { fundación }\end{array}$ & $\begin{array}{c}\text { Número de } \\
\text { empleados }\end{array}$ & $\begin{array}{c}\text { Rango de } \\
\text { facturación } \\
\text { (millones de } \mathbf{c} \text { ) }\end{array}$ & Forma jurídica & Ubicación \\
\hline (A1) RECLAM & 1940 & 26 & $1-5$ & S. L & A Coruña \\
\hline (A2) Está Pasando & 2014 & 40 & $1-5$ & S.L & Madrid \\
\hline
\end{tabular}

Las fuentes de información para la recolección de los datos son variadas, para poder ofrecer una triangulación y contraste de aquellas informaciones obtenidas de primera mano con otras fuentes secundarias (Stott y Ramil, 2014) (Villarreal-Larrinaga y Landeta Rodríguez, 2010). A continuación, se especifican las fuentes de información utilizadas en esta investigación:

A. Evidencia documental interna: páginas web de RECLAM (https://reclam.es) y Está Pasando (https://www.estapasandoagencia.com), archivos de presentaciones corporativas de ambas empresas, redes sociales (Instagram de ambas tas deben ser lo más neutrales posible, evitando que la redacción pueda influir en las respuestas; c) las preguntas deben hacerse una a una; d) las preguntas deben estar redactadas claramente, lo cual supone conocer los términos particulares de la cultura o del ámbito de los encuestados; y e) especial cuidado al hacer preguntas de "por qué", ya que fuerzan al entrevistado a realizar un proceso de intelectualización que debería ser realizado por quien realiza la investigación (Magadán-Díaz y Rivas-García, 2020).

Las entrevistas se llevaron a cabo presencialmente, fueron grabadas y posteriormente trans- 
critas y analizadas. Después, con el objetivo de contrastar los datos recogidos en las entrevistas, se llevó a cabo la consulta de otros documentos internos y de las páginas web de ambas empresas.

\section{ANÁLISIS DE LOS RESULTADOS Y DISCU- SIONES}

En este epígrafe se tratará de conocer cómo valoran y gestionan las dos agencias seleccionadas el patrimonio publicitario que se genera en el seno de su actividad, pero también otras cuestiones: ¿cuáles son las diferencias estructurales y organizativas de las dos agencias? ¿Influyen estas cuestiones en la importancia que dan al patrimonio publicitario? ¿cómo conservan su patrimonio publicitario? ¿qué concienciación tienen sobre el patrimonio publicitario? ¿cómo se documentan estas agencias? ¿consideran útil para su trabajo diario el patrimonio publicitario que han generado desde su creación?

A partir de las entrevistas realizadas y la consulta de material adicional (páginas web, redes sociales, material corporativo) se ha trabajado la información obtenida en función de las siguientes categorías:

1. Trayectoria y estructura.

2. Documentación y conservación de las campañas.

\subsection{Trayectoria y estructura}

Para este estudio de caso se han elegido dos agencias muy diferentes, especialmente en cuanto a la trayectoria. Mientras que RECLAM es la decana de las agencias de publicidad de Galicia, ya que nació en A Coruña en el año 1940 - en el año 2020 celebra su ochenta aniversario como agencia de publicidad y marketing independiente-, Está Pasando es una agencia creativa fundada en Madrid en el año 2014. Sin embargo, pese a la diferencia en la trayectoria, ambas son agencias medianas e independientes (véase Tabla I)

En el caso de RECLAM, el organigrama ha cambiado a lo largo de los años y actualmente la agencia gallega consta de un departamento de medios, un departamento digital, un departamento de cuentas, de marketing, de administración y por supuesto, el departamento creativo. Entre los servicios que ofrecen están: televisión, transformación digital, branding, gestión de influencers, servicios 360 o responsabilidad social, adaptándose a lo que demandan las marcas del mercado. Además, en los últimos años se han renovado tanto la oficina como la plantilla, favoreciendo la incorporación de trabajadores más jóvenes. Actualmente, A1 trabaja con algunos de los principales anunciantes galle- gos: Estrella de Galicia, A Banca o A Universidade de A Coruña, sin desatender tampoco a los pequeños clientes, como por ejemplo la Real Academia Gallega, con la que realizaron una campaña para introducir apoderamento (empoderamiento) en el diccionario de dicha institución.

En cuanto a la competencia, RECLAM considera que, actualmente, hay más competidores, teniendo en cuenta que en la comunidad gallega la constelación de agencias queda configurada de la siguiente manera: agencias de publicidad de una estructura mediana -considerando de quince a veinticinco empleados- hay cinco, de menos de quince encontramos aproximadamente diez, y luego una mayoría de pequeñas agencias de uno o dos empleados (entrevista a Lis Torrón, 2020). Las campañas más importantes suelen ser ejecutadas por las cinco agencias principales, previo concurso de agencias y los principales anunciantes gallegos son fundamentalmente Estrella Galicia, Inditex y A Banca:

"A Banca trabaja con Shackleton en Madrid y con otras como nosotros, claro, estas grandes marcas trabajan con distintas agencias. Si que es verdad que hay un exceso de oferta, pues no hay tanta demanda, ya que no existen tantas grandes marcas en Galicia. Hay muchas marcas medianas, como las conservas gallegas y otras de alimentación, pero en realidad no hacen tantas campañas publicitarias. A Banca suele trabajar con agencias gallegas, pero Estrella de Galicia trabaja con agencias a nivel nacional, al igual que Inditex, aunque Inditex tiene su propio departamento de publicidad y marketing". (Entrevista a Lis Torrón, 2020).

En contraposición a la larga trayectoria de $R E$ CLAM, la agencia creativa digital Está Pasando nació en 2014 fundada por dos hermanos: Borja Prieto y Jacobo Prieto, ambos con experiencia en comunicación digital, aunque en diferentes ámbitos. Mientras que Borja Prieto ha sido director de contenidos de la red social MySpace y de New Media Fox -entre otros-, Jacobo Prieto ha aportado su experiencia como creativo y diseñador en agencias como Proximity BBDO y en revistas del grupo Condé Nast (Vogue, GQ).

A2 trabaja con clientes multinacionales como Google, Netflix o Youtube, empresas del grupo Inditex -Bershka, Pull\&Bear-e instituciones como el Parlamento Europeo o la Agencia Española de Protección de Datos (AEPD). Estos clientes demandan estrategias digitales para conectar con el público zeta y millennial del que ya se ha hablado en este artículo. La agencia presta servicios de televisión, street marketing, social content, dirección creativa, diseño, producción de video y fotografía, ins- 
talaciones pop up, gestión de influencers y social media. Esta vocación digital influye en la estructuración de la empresa en la que el departamento creativo, dirigido por Jacobo Prieto asume el rol central de la agencia. Dicho departamento se divide en dos subdepartamentos: creatividad y diseño, y en él trabajan el director creativo, un supervisor creativo, dos duplas -formadas por un copy y un director de arte- y una dupla junior, además de becarios. Las funciones principales de este departamento, además de liderar la parte creativa de la agencia, son (Figura 2):

Figura 2. Funciones del departamento creativo de la agencia Está Pasando.

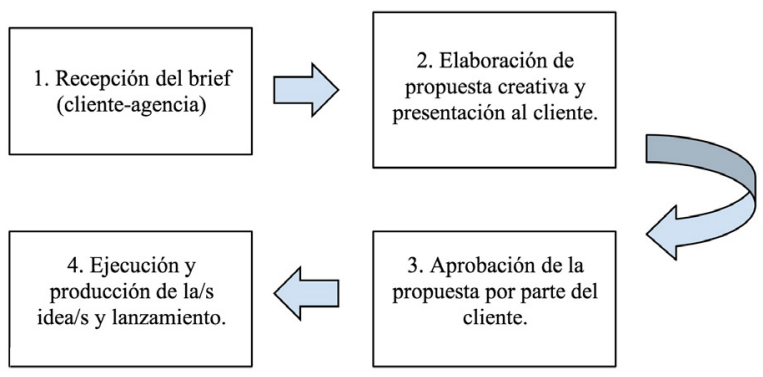

Fuente: entrevista con Jacobo Prieto, 2020.

\subsection{Conservación de las campañas y docu- mentación}

La agencia RECLAM fue fundada por Domingo Torrón Villares en 1940, que era en aquel momento un auténtico visionario de la publicidad, en un país y una región española en la que la publicidad todavía se encontraba en mantillas, con pocas agencias -apenas cincuenta y cinco en todo el país (Fernández Poyatos, 2010)- y con una visión bastante anticuada y propia de un país atrasado cultural y económicamente que, además, acababa de salir de una guerra civil. El fundador de la agencia, Domingo Torrón, tenía profundos conocimientos de lo que estaban haciendo en publicidad las mejores agencias de los Estados Unidos y apoyado por su esposa, Carmen Fraile, que traducía del inglés, el francés y el ruso, comenzaron a trabajar inspirados en las revistas y libros publicitarios, sobre todo estadounidenses, e incluso se abonaron a agencias que ofrecían en sus books anuncios que les permitían adaptar a estas agencias más pequeñas. Al principio, RECLAM se dedicaba a contratar espacios en los medios de comunicación, principalmente periódicos, para promocionar comercios y esos espacios de los periódicos se llamaban reclamos, de ahí el nombre de RECLAM. Algún tiempo más tarde, la agencia comenzó a ofrecer no sólo la contratación de espacios, sino también la creatividad de las piezas (entrevista a Lis Torrón, 2020).

RECLAM ha pasado por tres períodos bien definidos y en cada uno de ellos se encuentra al frente algún miembro de la familia Torrón, pero perteneciente a una generación distinta:

Figura 3. Etapas de la agencia $R E C L A M$ (1940-actualidad).

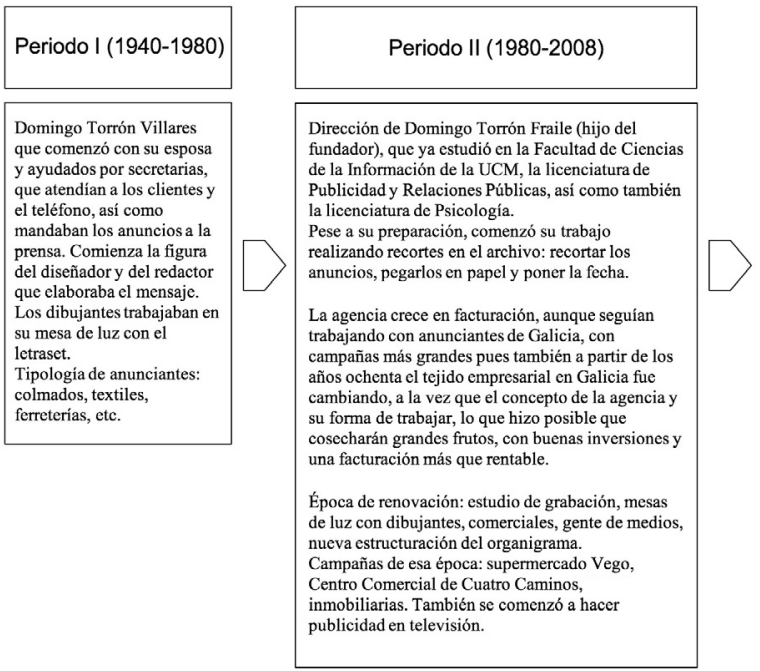

Periodo III (2008-actualidad)

En el tercer periodo de RECLAM asumen la dirección
los dos hijjos del dueño, Domingo Torrón Alabaú y Lis
Torrón Alabaú por el fallecimiento prematuro de su
padre. La preparación específica de Domingo Torrón
licenciado en ADE con especialización en Marketing y
Lis Torrón en Publicidad, además de estudios
internacionales y conocimiento de idiomas, da a la
agencia una nueva impronta más acorde con la
publicidad del siglo XXI. La idea de ambos hermanos
desde el principio era cambiar el modelo de negocio, aún
compartiendo la dirección con el abuelo.
Cambio de plantilla: nuevos perfiles, nuevo talento,
nuevas preocupaciones (como el medio ambiente) y
nueva creatividad.
Anunciantes nacionales e internacionales: Estrella
Galicia, A Banca, A Universidade de A Coruña, FSE,
Xunta de Galicia, Super Bock.

Fuente: entrevista a Lis Torrón (2020).

Entre las preocupaciones de la agencia RECLAM se encuentra la conservación del patrimonio publicitario que se ha generado desde sus inicios. Por este motivo, se han conservado prácticamente todas las campañas y piezas, desde los antiguos reclamos que aparecían en los periódicos en los años cuarenta, hasta lo producido en la actualidad. Sin embargo, es cierto que algunos de aquellos reclamos y anuncios de los años cuarenta y cincuenta se han perdido y aquello que se conserva se encuentra en cajas en un gran archivo que ocupa varias salas de la antigua oficina de la agencia. Todo ese patrimo- 
nio publicitario necesita un tratamiento -incluyendo análisis documental y catalogación- para facilitar su búsqueda y recuperación. Llevar a cabo esa labor de conservación que la agencia tiene pendiente, pero que está interesada en realizar, supone tener una gran parte de la publicidad que se ha hecho en Galicia en estos últimos ochenta años. Respecto al patrimonio generado actualmente, RECLAM conserva las campañas de forma digitalizada, es decir, se vuelca todo en un servidor y cada cierto tiempo se hace un back up o copia de seguridad, se revisa lo conservado y se guarda en discos duros, además de la conservación digital en la página web.

La agencia Está Pasando coincide con RECLAM en la custodia de sus campañas en su página web, pero también en las redes sociales, especialmente en Instagram. Esto no solo supone la preservación de su trabajo, sino también la autopromoción de su trabajo para captar nuevos clientes y por ello consideran que la tarea de actualizar y cuidar sus redes y su página web es muy relevante también a nivel interno, e incluso hay personal contratado cuya función es atender constantemente estos canales. Sin embargo, en esta agencia no se realiza ninguna copia de seguridad en servidores, lo cual resulta un peligro porque pueden darse circunstancias externas (bloqueo de cuentas en redes sociales, caída del servidor de la página web) que supongan en última instancia la pérdida de los documentos almacenados. Otro sistema que se utiliza en Está Pasando para conservar sus campañas es la elaboración de credenciales, es decir, una carta de presentación de la agencia en formato Power Point o PDF. En esta agencia consideran que los tiempos y plazos para concebir, diseñar y finalmente, lanzar una campaña son muy ajustados para pensar en que ese trabajo pueda ser, en un futuro, considerado patrimonio $y$, si bien reconocen que deberían plantearse la conservación de su trabajo de manera más sistemática, creen que la tarea de crear un archivo publicitario le corresponde a la marca o anunciante (entrevista a Jacobo Prieto, 2020).

Sin embargo, resulta interesante analizar algunas de sus campañas (por ejemplo-Figuras 2 y 3 )

Figura 4. Anuncio de la perfumería Garrote, 1952.

Figura 5. Vai de Peixe, Xunta de Galicia, 2019.

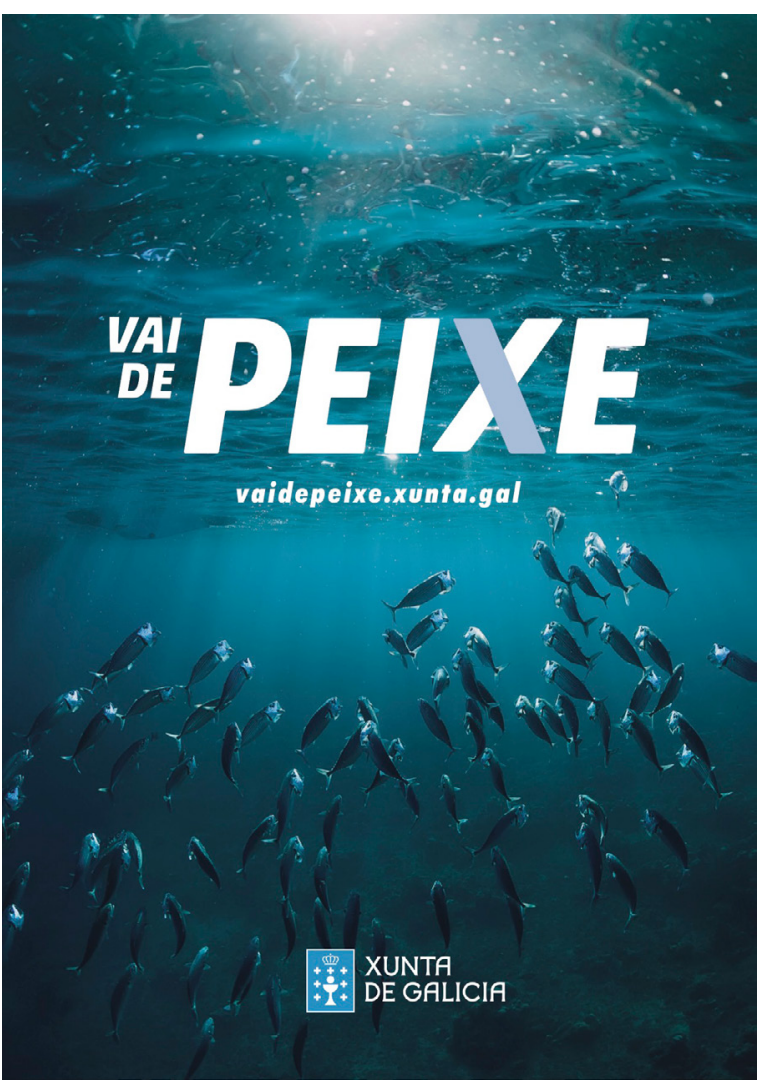

Fuente: RECLAM 
para comprender que, pese a la escasa concienciación sobre el patrimonio que existe en esta agencia, la labor de documentación ${ }^{6}$ se lleva a cabo meticulosamente. La principal fuente de información sería el propio brief que les proporciona la agencia y que sirve como punto de partida del proceso; este documento es fundamental ya que ofrece información relativa al contexto de la marca, datos socioeconómicos del sector, objetivos de la campaña, presupuesto, público objetivo o target, fechas de entrega y lanzamiento, material adicional -si lo hubiera, por ejemplo, en el caso de trabajar en la promoción de una serie, los dos primeros capítulos-, entre otros.

En este sentido es preciso señalar que también consideran a la hora de documentarse otras vertientes del patrimonio social, como el generado por los medios de comunicación -véase Figura 6, cartel de la campaña creada para la plataforma Netflix en la que se utilizaron irónicamente los mensajes de Whatsapp enviados por Mariano Rajoy a Luis Bárcenas para anunciar la serie Narcos- o el artístico,

Figura 6. Anuncio de Narcos, Netflix, 2017.

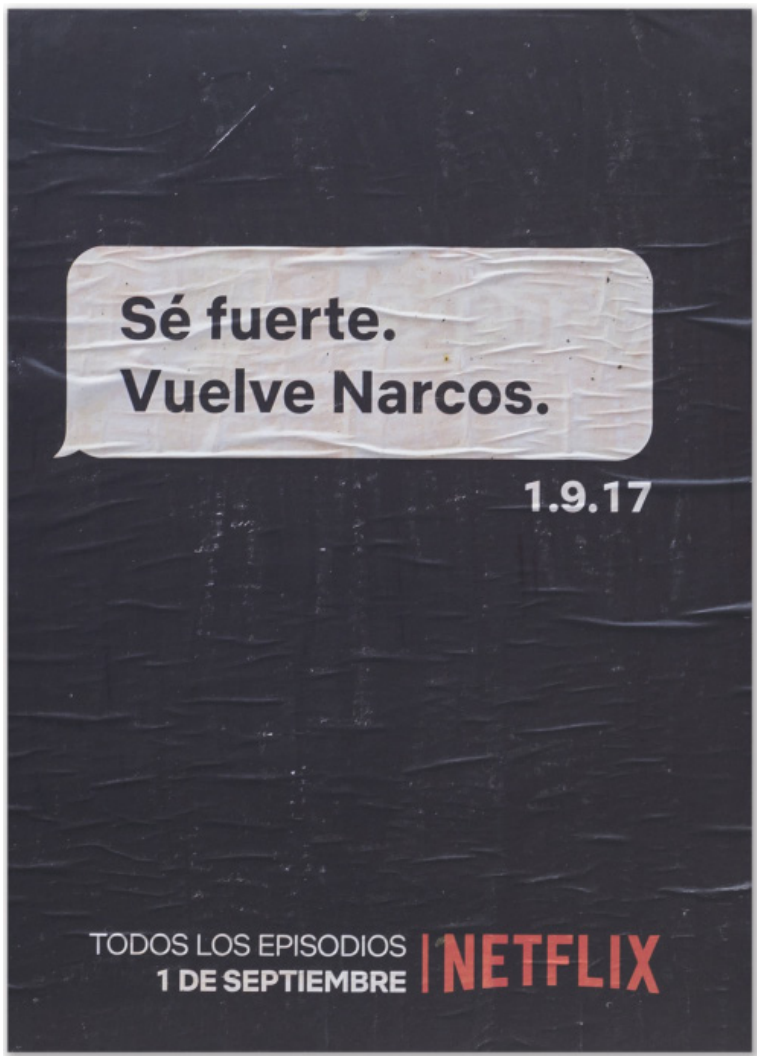

como se observa en la Figura 7 que muestra un cartel enmarcado en una acción de street marketing de Etnia Barcelona en la que distintos fotógrafos reinterpretaron obras de arte que después fueron intervenidas por artistas urbanos, en este caso, "La dama del unicornio" de Rafael. Otra iniciativa que se lleva a cabo con el fin de documentarse sobre buenas prácticas de la competencia -con relación a soportes, nuevos medios o influencerses la elaboración de informes semanales -benchmarking- o trimestrales -trend reports, o informes de tendencias-, generalmente confeccionados por un/a ejecutivo/a de cuentas o un becario. En ningún caso, existe en ningunas de las dos agencias estudiadas un profesional de la documentación que se encargue de asistir en estas tareas de investigación o conservación del patrimonio.

\section{CONCLUSIONES}

Este artículo alcanza el objetivo que se planteaba: conocer cómo dos agencias publicitarias españolas valoran, gestionan y conservan el patrimonio
Figura 7. \#BeAnartist, Etnia Barcelona, 2018.

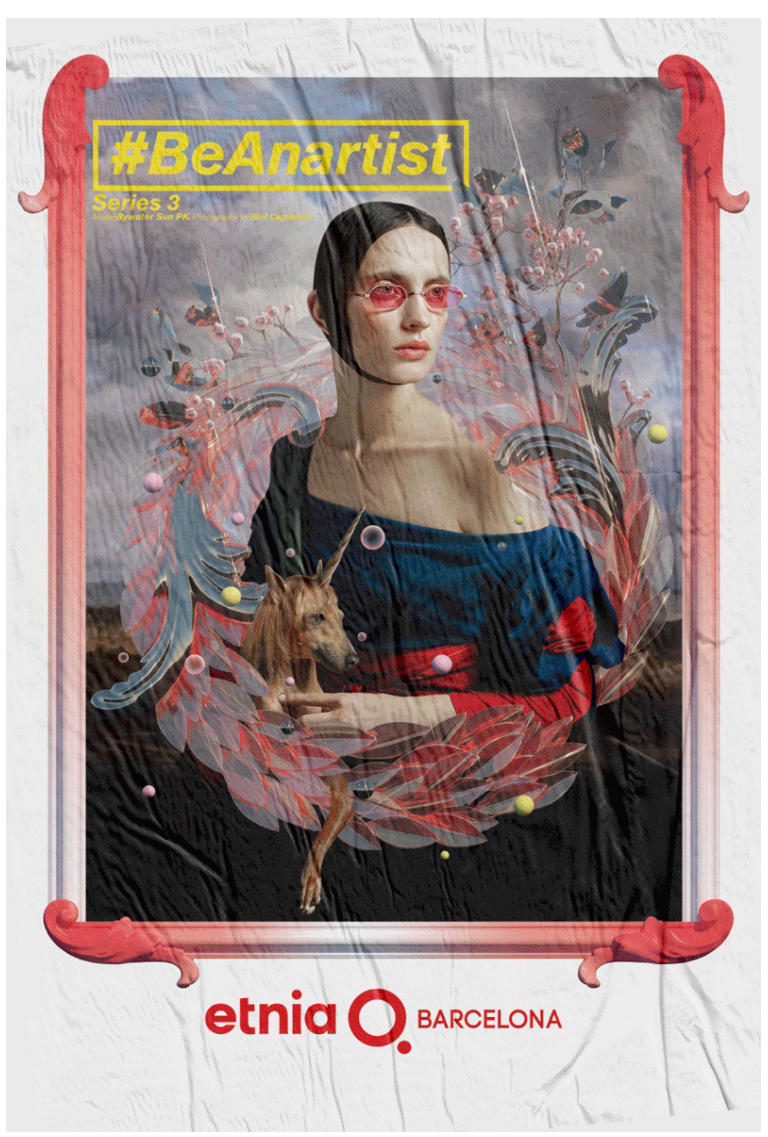

Fuente: Está Pasando.com 
publicitario que generan en su actividad profesional. Incluso puede confirmarse una hipótesis que subyace a lo largo de esta investigación y que es la escasa concienciación en torno al patrimonio publicitario -en estas dos agencias, pero que puede hacerse extensible a otras- por la dinámica de trabajo tan inmediata inherente a la actividad publicitaria.

En primer lugar, RECLAM, es una agencia de publicidad con una trayectoria importante $y$, por tanto, el patrimonio generado durante casi un siglo puede dar cuenta de cómo la sociedad ha cambiado en ese período y de los gustos de los consumidores desde los años cuarenta del siglo veinte. Sin embargo, este extenso recorrido genera una paradoja: por un lado, la percepción de RECLAM como una agencia antigua y obsoleta por parte del público, no de los profesionales del sector (entrevista a Lis Torrón, 2020); y, por otro lado, la riqueza patrimonial que atesoran en su archivo. Es urgente que este archivo reciba el tratamiento documental que merece, no sólo para garantizar la conservación gracias a la digitalización del archivo, sino también para una posible difusión en sus redes sociales o en página web. En ese sentido, RECLAM celebrará su ochenta aniversario compartiendo en sus redes los anuncios más curiosos y excéntricos de su historia (entrevista a Lis Torrón, 2020).

En lo que respecta a la documentación, es una cuestión acuciante la incorporación de perfiles profesionales del área especializados en publicidad que asuman las tareas que otras figuras están realizando actualmente sin la formación o el tiempo necesario. Estas labores pueden ser de carácter interno -elaboración de informes de tendencias, benchmarking, tratamiento documental del material de archivo, conservación, digitalización de las campañas- o de carácter externo como, por ejemplo, la gestión de compra de material de archivo ya sea fotográfico o audiovisual, necesario en ocasiones para la elaboración de piezas audiovisuales o para dotar de contenido a eventos promocionales, entre otros.

Otra cuestión que merece ser recogida en estas conclusiones es la perpetuación del debate acerca de quién debe conservar y gestionar el patrimonio, ¿debe ser tarea del anunciante o de la agencia? Este debate se recoge en el marco teórico del artículo y se confirma a lo largo del epígrafe cuatro donde la agencia Está Pasando constata que, aunque sería bueno que tanto agencia como anunciante creasen su propio archivo, la responsabilidad final de acometer dicha tarea sería de la empresa anunciadora. Posiblemente estemos ante una posición cortoplacista, ya que la conservación del trabajo producido por una agencia puede reunir un valioso patrimonio publicitario que incluso puede reutilizarse en un futuro por esa misma agencia -como es el caso de la recuperación del primer logotipo de Metro para la conmemoración de su centenario en 2019, o de la revisión del famoso spot publicitario de Telefónica cuyo claim era "Hola, soy Edu, feliz Navidad" por parte de Volkswagen en 2018, generando un interesante crossover entre marcas- o por otras agencias o empresas, produciendo así un ciclo de valor añadido.

Y no sólo eso, desde un punto de vista histórico, el trabajo de una agencia arroja luz sobre los hábitos de consumo o de ocio de una sociedad en un momento determinado y también sobre las técnicas creativas y estéticas utilizadas en el pasado y que, por qué no, pueden recuperarse -si se conocen- para trabajar en una nueva campaña. Por este motivo, también se hace necesario aquello que muchos autores e investigadores llevan tiempo reclamando: un museo de la publicidad española que realice la labor de investigación y conservación de archivos publicitarios, como el de la agencia RECLAM y tantas otras cuyos fondos no pueden perderse ni destruirse, y lo pongan a disposición del público para así, coadyuvar a la concienciación sobre este tipo de patrimonio tan poco conocido y valorado, como se ha comprobado en esta investigación.

\section{AGRADECIMIENTOS}

Esta investigación se ha realizado en el marco del grupo de investigación UCM-GR17-970831 Patrimonio Digital en Medios de Comunicación (PADEM) de la Facultad de Ciencias de la Información, UCM.

\section{ACKNOWLEDGEMENTS}

This research has been carried out within the framework of the research group UCM-GR17-970831 Digital Heritage in Media (PADEM) of the School of Communication, UCM.

\section{NOTAS}

${ }^{1}$ Quizá un ejemplo significativo y reciente de la importancia del patrimonio publicitario en la actualidad sea la campaña conmemorativa del centenario de Metro (19192019), en la que, entre otras acciones, se utilizó el logotipo de 1919 y los trenes de la Línea 1 se decoraron imitando a los originales de la época.

2 Un dato para ilustrar lo anterior es el descenso de la inversión publicitaria un $14,9 \%$ en 2009 respecto de 2008, un total de 2.216,3 millones de euros menos (Infoadex, 2010, citado en Cabezuelo-Lorenzo, 2014).

3 Debe aclararse que los medios controlados, anteriormente denominados medios convencionales, son Televisión, Radio, Cine, Digital, Exterior, Diarios, Revistas y Dominicales. Por otro lado, los medios estimados, o below 
the line, incluyen actos de patrocinio, RSC, branded content, influencers, entre otros.

${ }^{4}$ Actualmente, conviven cuatro generaciones diferentes: los baby boomers (nacidos entre 1945-1964), la generación $X$ (nacidos entre 1965-1979), millennials (nacidos entre 1980 y 1999) y la generación $Z$ (nacidos entre el año 2000 y 2010). Las dos últimas generaciones mencionadas se consideran nativas digitales.

${ }^{5}$ Es preciso señalar que los perfiles profesionales más demandados en el sector publicitario español en 2018 fueron los de Digital Marketing Manager \& Communication Director y Community Manager (Benavides-Delgado, J. y otros, 2019).

${ }^{6}$ Las autoras han detectado que el argot publicitario, conocido por sus anglicismos, la documentación recibe el nombre de research.

\section{REFERENCIAS}

Álvarez-Álvarez, C y San Fabián-Maroto J.L, (2012): La elección del estudio de caso en investigación educativa, Gazeta de Antropología, 28 (1), artículo 14, Recuperado de: https://digibug.ugr.es/handle/10481/20644 [Fecha de consulta: 14/05/2020]

Benavides-Delgado, J., Alameda, D., Fernández-Blanco, E., y López de Aguileta-Clemente, C. (2019): 2019. Observatorio de la publicidad en España. Madrid: Asociación Española de Anunciantes.

Cabezuelo-Lorenzo, F. (2014): Cinco años de crisis en el mercado de la comunicación (2008-2013). Historia y Comunicación Social. Vol. 18. No Especial Diciembre, 703-715. https://doi.org/10.5209/rev_HICS.2013. v18.44358

Castro-Monge, E. (2010): El estudio de casos como metodología de investigación y su importancia en la dirección y administración de empresas, Revista Nacional de Administración, 1 (2): 31-54 Julio-Diciembre, 2010, 31-54

Coronado e Hijón (2000) De la publicación de la fotografía a la fotografía publicada: en torno a los orígenes decimonónicos de la fotografía publicitaria, Revista Latina de Comunicación Social, 32.

Cortés-González, A. (2011): La publicidad institucional en España. Una década en perspectiva, Razón y Palabra, 75.

De Andrés del Campo, S. y González-Martín, R. (2010) Referencias al medio ambiente en los mensajes publicitarios investigación de la publicidad en España entre 2006 y 2007, AdResearch: Revista Internacional de Investigación en Comunicación, 2, 6-25. https://doi. org/10.7263/adresic-002-01

De Salas-Nestares, I., Martínez-Sáez, J. y Roca-Hueso, V. (2019). Los nuevos perfiles profesionales como elemento transformador de la industria publicitaria. Revista Mediterránea de Comunicación/Mediterranean Journal of Communication, 10 (2), 11-28. https:// www.doi.org/10.14198/MEDCOM2019.10.2.16

Eguizábal-Maza, R. (2001): Fotografía publicitaria. Madrid: Cátedra.

Eguizábal-Maza, R. (2003): La fotografía moderna, de la publicidad a la propaganda, A distancia, 161-171.

Eguizábal-Maza, R. (2011) Historia de la publicidad, Madrid: Fragua.
Extra Digital (2019): ¿Qué marcas lideran la inversión publicitaria en Galicia? Disponible en: https://www. extradigital.es/galicia-que-marcas-lideran-la-inversion-publicitaria-en-galicia/ [Fecha de consulta: 11/06/2020]. https://www.raco.cat/index.php/questionespublicitarias/article/view/v15-fernandez

Fernández-Poyatos, M.D. (2010) Las primeras agencias españolas de publicidad (1912-1934), Questiones Publicitarias, 1 (15), 52-71. https://doi.org/10.5565/ rev/qp.83

Fernández-Poyatos, M.D. (2013) Propuestas cronológicas para la Historia de la publicidad, Historia y Comunicación Social. 18. (N. Esp.), 267-277. https://doi. org/10.5209/rev_HICS.2013.v18.43965

González-Solas, J. (com.) (2018): Grupo 13. Publicidad entre el arte y el diseño. Exposición celebrada en el Museo Nacional de Artes Decorativas, Madrid. Del 21 de noviembre de 2018 al 31 de marzo de 2019. Madrid: Museo Nacional de Artes Decorativas.

Infoadex (2008，2009，2010，2011，2012，2013，2014, 2015, 2016, 2017, 2018, 2019, 2020): Resumen. Estudio Infoadex de la inversión publicitaria en 2008. Madrid: Infoadex.

Magadán-Díaz, M.; Rivas-García, J. I. (2020). El impacto disruptivo del libro electrónico sobre la cadena de valor editorial española: un estudio de casos. Revista Española de Documentación Científica, 43 (1), e258. https://doi.org/10.3989/redc.2020.1.1650

Marcos-Recio, J.C. (2002) Evolución y desarrollo de la documentación en el campo publicitario: recursos para optimizar una campaña, Documentación de las Ciencias de la Información, 25, 235-265.

Marcos-Recio, J.C. Sánchez-Vigil, J.M, y Villegas-Tovar, R. (2005): La imagen en la publicidad: la fotografía al servicio de la documentación publicitaria y los derechos de autor, Scire: Representación y organización del conocimiento, 11 (2), (Ejemplar dedicado a Documentación digital en los medios de comunicación y la publicidad: análisis y experiencias), 119-132.

Marcos-Recio, J.C., De la Cuadra-Colmenares, E., Fernández-Sande, M. (2018) Evolución histórica y perspectivas de futuro en la gestión del patrimonio radiofónico, cinematográfico, televisivo y publicitario, Revista General de Información y Documentación 28 (2), 659683. https://doi.org/10.5209/RGID.62843

Marcos-Recio, J.C (2018): El patrimonio menos visible, el publicitario, Marcos-Recio J.C (coord.) Lo efímero de la comunicación. Cómo preservar los contenidos en la era digital. Barcelona, Ed. UOC.

Montañés, F. (2015): Una historia de la publicidad y el consumidor en España. Madrid: Asociación Española de Anunciantes.

Museo Virtual de Arte Publicitario (MUVAP) (2001): Museo Virtual de Arte Publicitario (MUVAP). Disponible en: https://cvc.cervantes.es/artes/muvap/default.htm [Fecha de consulta: 15/05/2020]

Orbea-Mira, (2008): Publicidad y consumo en la España de la transición, Comunicación: Memoria, Historia y Modelos (coord. por Emilio Feliu García), 533-538.

Pacheco Rueda, M. (1998): Dimensión social de la publicidad exterior, Revista Latina de Comunicación Social, 8. 
Pacheco Rueda, M. (2000): La historia de la publicidad exterior en España, Control: La publicidad desde 1962, 39 (456), 68-69.

Pacheco Rueda, M. (2004): Notas en torno a la función social de la publicidad exterior, en Publicista de la publicidad, la comunicación y el marketing, 104, 30-37.

Pacheco Rueda, M. (2008): Cinco décadas de publicidad exterior en España, en Comunicación: Memoria, Historia y Modelos (coord. por Emilio Feliu García), 496-503

Publidocnet: Centro Documental para la conservación del patrimonio publicitario español. Disponible en: publidocnet.es [Fecha de consulta: 24/05/2020]

Sánchez-Vigil, J.M (2009): Fotografía y publicidad: aspectos informativos y documentales, en Revista General de Información y Documentación. 19 (1). Madrid: Servicio de Publicaciones UCM, 415-418.

Stott, L. y Ramil, X (2014): Metodología para el desarrollo de estudios de caso. Madrid: Centro de Innovación en tecnología para el desarrollo humano de la Universidad Politécnica.
Turner, D. W., III (2010). Qualitative interview design: A practical guide for novice investigators. The Qualitative Report, 15 (3), 754-760. Disponible en: http://www. nova.edu/ssss/QR/QR15-3/qid.pdf [Fecha de consulta: 14/05/2020].

Vicente-Domínguez, A. M. (2017). MUVAP (2001-2016): museo virtual que documenta la historia de la publicidad y el diseño gráfico en España, Pensar la Publicidad, 11, 33-51. https://doi.org/10.5209/PEPU.56392

Villarreal-Larrinaga y Landeta-Rodríguez, (2010): El estudio de casos como metodología de investigación científica en dirección y economía de la empresa. Una aplicación a la internacionalización, Investigaciones Europeas de Dirección y Economía de la Empresa 16 (3), 2010, 31-52

We Are Social (2020): Digital Report 2020 España. Disponible en: https://wearesocial.com/es/blog/2020/02/digital-2020-en-espana [Fecha de consulta: 26/05/2020] 